\title{
Estimating air-sea fluxes of heat, freshwater, and momentum through global ocean data assimilation
}

\author{
D. Stammer, ${ }^{1}$ K. Ueyoshi, ${ }^{1}$ A. Köhl, ${ }^{1}$ W. G. Large, ${ }^{2}$ S. A. Josey, ${ }^{3}$ and C. Wunsch ${ }^{4}$ \\ Received 4 August 2003; revised 8 December 2003; accepted 24 February 2004; published 21 May 2004.
}

[1] ECCO state estimation results from 10 years during the World Ocean Circulation Experiment are used to assess the quality of surface flux adjustments made to the initial NCEP re-analysis-1 products. During the state estimation procedure, surface fluxes are adjusted together with initial temperature and salinity conditions so that the model simulation becomes consistent with ocean observations. Independent estimates of the adjustments from bulk formula and regional field observations are also employed to evaluate the results. Buoyancy flux adjustments are found to be within the crude prior error bars on these fields. Outside the boundary current regions, they are consistent with known large-scale deficiencies in the NCEP products. Wind stress adjustments are also everywhere within the prior error bars, but exhibit regional small-scale features that reflect ocean model failures to resolve intense boundary currents. On large scales, the inferred adjustments to NCEP wind stress fields are consistent with inferences made from satellite wind stress measurements. Further improvements in the surface flux estimates obtained through state estimation procedures are anticipated as the estimation procedure becomes more complete by including the use of improved prior error covariance information, and as the ocean model becomes more skillful, for example, in simulating boundary currents by increasing its resolution. INDEX TERMS: 4504 Oceanography: Physical: Air/sea interactions (0312); 4512 Oceanography: Physical: Currents; 4263 Oceanography: General: Ocean prediction; 4255 Oceanography: General: Numerical modeling; KEYWORDS: data assimilation, air-sea fluxes, ocean synthesis

Citation: Stammer, D., K. Ueyoshi, A. Köhl, W. G. Large, S. A. Josey, and C. Wunsch (2004), Estimating air-sea fluxes of heat, freshwater, and momentum through global ocean data assimilation, J. Geophys. Res., 109, C05023, doi:10.1029/2003JC002082.

\section{Introduction}

[2] Air-sea fluxes of momentum, heat, and moisture are an essential ingredient in the understanding of atmospheric and oceanic circulations as well as the overall climate system. Despite recent advances, substantial uncertainties remain in estimates of these properties, and, indeed, quantitative estimates of their errors are themselves almost nonexistent. This general uncertainty severely handicaps the study of climate and of the underlying skill of models used to depict it.

[3] The Working Group on Air-Sea Fluxes (WGASF) [2000] reviews the state-of-the art of air-sea flux estimation from various methods including the re-analysis products, but also direct bulk-formula calculations and calculations from atmospheric state estimate residuals. Ongoing re-

\footnotetext{
${ }^{1}$ Scripps Institution of Oceanography, La Jolla, California, USA.

${ }^{2}$ Oceanography Section, National Center for Atmospheric Research, Boulder, Colorado, USA.

${ }^{3}$ James Rennell Division, Southampton Oceanography Centre, Southampton, UK.

${ }^{4}$ Department of Earth, Atmospheric, and Planetary Sciences, Massachusetts Institute of Technology, Cambridge, Massachusetts, USA.

Copyright 2004 by the American Geophysical Union. 0148-0227/04/2003JC002082\$09.00
}

analysis efforts at numerical weather prediction centers such as the European Centre for Medium Range Weather Forecasts (ECMWF) [Gibson et al., 1997] and the National Centers for Environmental Prediction (NCEP) [Kalnay et al., 1996] provide estimates of 6-hourly global air-sea flux fields on regular grids. A growing number of studies however, show significant deficiencies in these products [e.g., Milliff et al., 1999; Wang and McPhaden, 2001; Smith et al., 2001; Sun et al., 2003]. Among others, problems exist with the tropical wind stress and its divergence, near-surface humidity, polar temperatures, bulk flux algorithms, precipitation, clouds in the South Pacific Convergence Zone, and the sea-surface albedo.

[4] An alternative method for estimating air-sea fluxes, which has only recently become feasible, relies upon the availability of accurate estimates of the oceanic state and, in effect, calculates those air-sea fluxes which best reproduce what is observed of the time-evolving ocean state. We focus here on this new method, attempting to evaluate it relative to other such estimates. The general methodologies of ocean state estimation are described by Wunsch [1996], Malanotte-Rizzoli [1996], and Fukumori [2001], and as employed in practice by Stammer et al. [2002, 2003] and Köhl et al. [2002]. A summary of the method is that it combines a great variety of oceanic observations over long time intervals, in such a way that a given ocean circulation 
model describes the time and space evolution of the oceanic state in a dynamically consistent manner. Air-sea fluxes become part of the "control vector" that is adjusted to bring the model into consistency (within error limits) with the data.

[5] Several earlier examples exist. Among those, Bonekamp et al. [2001] uses surface wind stress as a control vector over 2-week periods in the tropical Pacific Ocean. Here our goal is much more ambitious: to produce optimal estimates of the oceanic state and of the control vector (of which air-sea fluxes are only one part), over the global ocean for a decade. We make use of a solution of the "Estimating the Circulation and Climate of the Ocean" (ECCO) Consortium available on a $1^{\circ}$ spatial grid over the 10-year period 1992 through 2001 [Köhl et al., 2002; Lu et al., 2002] which builds on an earlier, similar, $2^{\circ}$ solution of Stammer et al. [2002, 2003].

[6] A. Köhl et al. (Seasonal changes in the ECCO global synthesis, submitted to Journal of Physical Oceanography, 2004) show that the constrained model displays considerable skill in reproducing many of the qualitative and quantitative features of the ocean circulation and transports. As will be shown also below, the ECCO $-1^{\circ}$ meridional heat transports are mostly consistent with the estimates of Ganachaud and Wunsch [2003], even in the North Atlantic where the previous $2^{\circ}$ estimate was biased low by $0.5 \mathrm{PW}$.

\section{Independent Estimates}

[7] To investigate the question of whether the ECCO estimates represent true improvements to the NCEP reanalysis-1 fluxes [Kalnay et al., 1996], the ECCO fluxes will be compared here with independent estimates available from bulk formula and regional field observations, including equatorial mooring data [McPhaden et al., 1998] and scatterometer fields. This discussion is not straightforward because errors abound in all estimated fields, whatever their source or methodology. For example, a recent careful analysis based on ship observations, the Southampton Oceanography Centre (SOC) climatology [Josey et al., 1999], showed a global mean heating of about $30 \mathrm{~W} / \mathrm{m}^{2}$, which cannot be real. Grist and Josey [2003] subsequently removed much of this bias by adjusting, on a global basis, individual flux components using various hydrographic measurements of the ocean heat transport as constraints. The resulting fields, which below are referred to as the "adjusted SOC climatology" (ASOC), have a global mean net ocean heat loss to the atmosphere of $2 \mathrm{Wm}^{-2}$. These ASOC fields provide good agreement with independent estimates of the ocean heat transport obtained using residual techniques [Trenberth et al., 2001] and more recent hydrographic measurements (see Grist and Josey [2003] for details). However, it is important to note that biases remain in the ASOC fields at scales smaller than the regions spanned by the available hydrographic constraints. In particular, comparisons with buoy measurements in the Subduction Experiment region of the North Atlantic indicate that the adjusted fluxes significantly overestimate the heat loss in this region by $30 \mathrm{~W} / \mathrm{m}^{2}$. Similar or even larger biases can be expected over western boundary current regions.
[8] An alternative approach that addresses known deficiencies in the NCEP re-analysis surface fluxes has been adopted by W. G. Large and S. Yeager (personal communication, 2004) (hereinafter LY04), following the earlier approach of Large and Nurser [2001]. NCEP surface radiation and precipitation are replaced by satellite-based estimates. In their approach, the NCEP near-surface wind, air temperature, and humidity are objectively corrected by comparison with satellite scatterometer winds, near-shore surface stations, and ocean buoy and ship data, then used together with the historical sea surface temperature record in observationally based bulk formula, to produce the air-sea fluxes of momentum, sensible and latent heat, and evaporation. A complete set of fluxes is available as part of the LY04 data set starting at the beginning of the satellite era of 1983. Over the entire 17-year period the global average LY04 heat flux into the ocean is about $2 \mathrm{~W} / \mathrm{m}^{2}$; however, it is nearly zero over the ECCO years (1992-2001). For the following comparison we will use the 10-year averaged LY04 fluxes from 1991 through 2000.

[9] The comparison of the ECCO synthesis results with the SOC, LY04, and other data sets reveals information about uncertainties, residing in the ECCO ocean model, in the NCEP re-analysis-1 atmospheric model, and in the flux climatologies themselves. Because of the errors present in all fields, our strategy is primarily one of comparison. In cases when the ECCO-estimated adjustments to NCEP surface forcing fields are consistent with independent assessments of NCEP, such as the SOC or LY04 fluxes, we regard that as support for skill in the ECCO results. In some regions, such as western boundary currents, the results are ambiguous, and these will have to be the focus of future efforts. Because uncertainties in all available flux products increase significantly over the Southern Ocean, this region receives less attention here.

[10] For the later interpretation of results, it is important to recall that the ECCO flux estimates are not entirely independent of either the SOC adjusted fluxes or the LY04 fluxes. As an example, both ECCO and SOC utilize ocean hydrographic data to adjust the solution and thus the heat flux. However, the ECCO physical model is time dependent and much more complex than the simple static box model used in the ASOC approach to estimate divergence of ocean heat transport from hydrographic sections.

[11] In addition, the ECCO fluxes start from the NCEP reanalysis-1 surface momentum, heat, and freshwater fluxes. Details on how those fluxes were computed are provided by Kalnay et al. [1996]. Those fluxes are, however, different from fluxes resulting from air temperature, humidity, and bulk formula which form the basis for the LY04 analysis. The subsequent ECCO adjustments are based on ocean dynamics and ocean observations, while the LY04 differences from NCEP involve the use of satellite-based fluxes, different bulk formula, and corrections based on measurements of the near-surface atmosphere. Therefore there is no reason to suspect ECCO and LY04 differences from NCEP to be similar, other than if they are improving the flux estimates in both cases.

[12] Finally, the SOC fluxes are weakly connected to the NCEP and hence LY04 fluxes through the assimilation of ship surface flux observations (the basis of the SOC climatology) within the NCEP re-analysis. However, the 


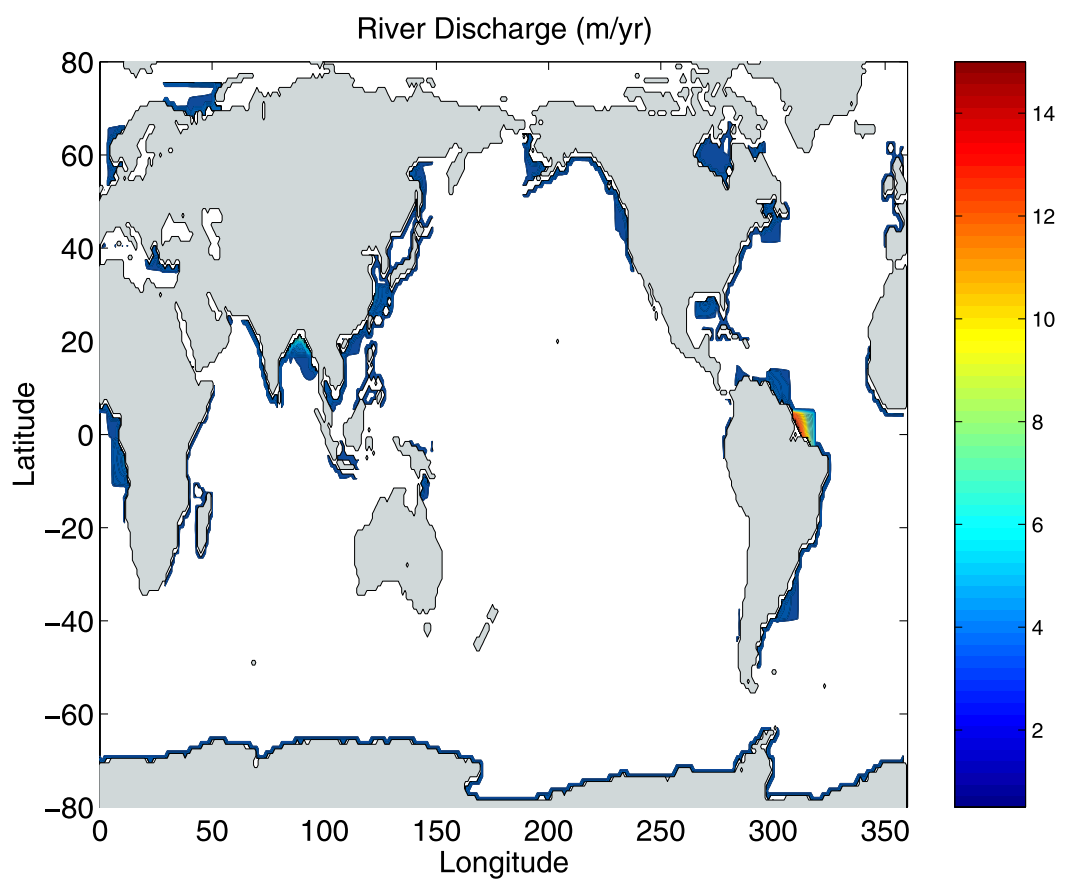

Figure 1. Mean river runoff from Large and Nurser [2001] which was incorporated into the forcing by adjusting the NCEP net freshwater fluxes. Observations gave the mean runoff at the mouths of about 200 gauged rivers [Perry et al., 1996], which typically accounts for 40 to $60 \%$ of the actual total value, and the remaining runoff into each basin from ungauged rivers was evenly distributed along its coast. The runoff was converted into the surface freshwater flux, by spreading it out over an area near its source. This spreading decreased exponentially with a $1000-\mathrm{km} e$-folding distance, as suggested by the observations of surface salinity off the mouths of the Amazon and Congo rivers. In the present computation, these values were not adjusted independently.

subsequent corrections are very different; solely empirical in the case of ASOC, and "objective" within the NCEP assimilation, followed by different empirical corrections by LY04. In summary, since the specifics in all three approaches are significantly different, for the present purpose we can consider all three flux climatologies as independent from each other and from the initial NCEP fields.

\section{Estimation Methodology}

[13] Only a brief summary of the estimation methodology is provided, as it is discussed at length in the references already cited. Unlike a number of other published ocean state estimates, our (computationally intensive) methodology is directed at achieving time-evolving fields that are consistent with the general circulation model, without any artificial sources or sinks being implied. We used the ECCO ocean general circulation model, which is derived from the MIT model [Marshall et al., 1997a, 1997b]. An adjoint code to the forward model was obtained from the automatic differentiation tool of Giering and Kaminski [1998] [see also Marotzke et al., 1999]. Prognostic variables are horizontal velocity, heat, and salt. Horizontal resolution is $1^{\circ}$ over $\pm 80^{\circ}$ latitude with 23 levels in the vertical. Free-slip bottom boundary conditions and non-slip boundary conditions at lateral walls are used. Laplacian viscosity and diffusivities are imposed, with $\nu_{h}=1 \times 10^{4} \mathrm{~m}^{2} / \mathrm{s}$ and $\kappa_{h}=$ $10^{2} \mathrm{~m}^{2} / \mathrm{s}$ and $\nu_{v}=10^{-3} \mathrm{~m}^{2} / \mathrm{s}$ and $\kappa_{v}=10^{-5} \mathrm{~m}^{2} / \mathrm{s}$, in the horizontal and vertical, respectively. The mixed layer is modeled with the "KPP" code of Large et al. [1994]. Eddies are parameterized by the method of Gent and McWilliams [1990]. Initial conditions were obtained from the Levitus et al. [1994a, 1994b] climatological January potential temperature and salinity fields, with the velocity field then adjusted over a 1-month period. The initial (a priori) model forcing consists of the first NCEP re-analysis daily surface heat and freshwater fluxes, and twice-daily wind stress. See Köhl et al. [2003] and http://www. ecco-group.org for details.

[14] In contrast to the earlier $2^{\circ}$-resolution calculation, river runoff was prescribed in the present estimate as timemean discharge. The imposed river inflow, shown in Figure 1, was obtained from estimates of the climatological difference between precipitation and evaporation over each continent, which were then partitioned between neighboring ocean basins (B. M. Fekete et al., An improved global spatially-distributed runoff data set based on observed river discharge and simulated water balance, unpublished report, Complex Systems Research Center, University of New Hampshire, 1999). Observed river discharge [Perry et al., 1996] is used to distribute some of this runoff near river mouths, with the remainder distributed evenly along each continent-ocean coastline. In this calculation, these values were added as time-constant to the surface freshwater flux fields. Amplitudes can be as large as the equivalent of $20 \mathrm{~m} / \mathrm{yr}$ of precipitation over the Amazon region, i.e., an order of magnitude larger than the maximum net freshwater from the atmosphere. 
Global 1 degree WOCE Synthesis 1992 through 2001

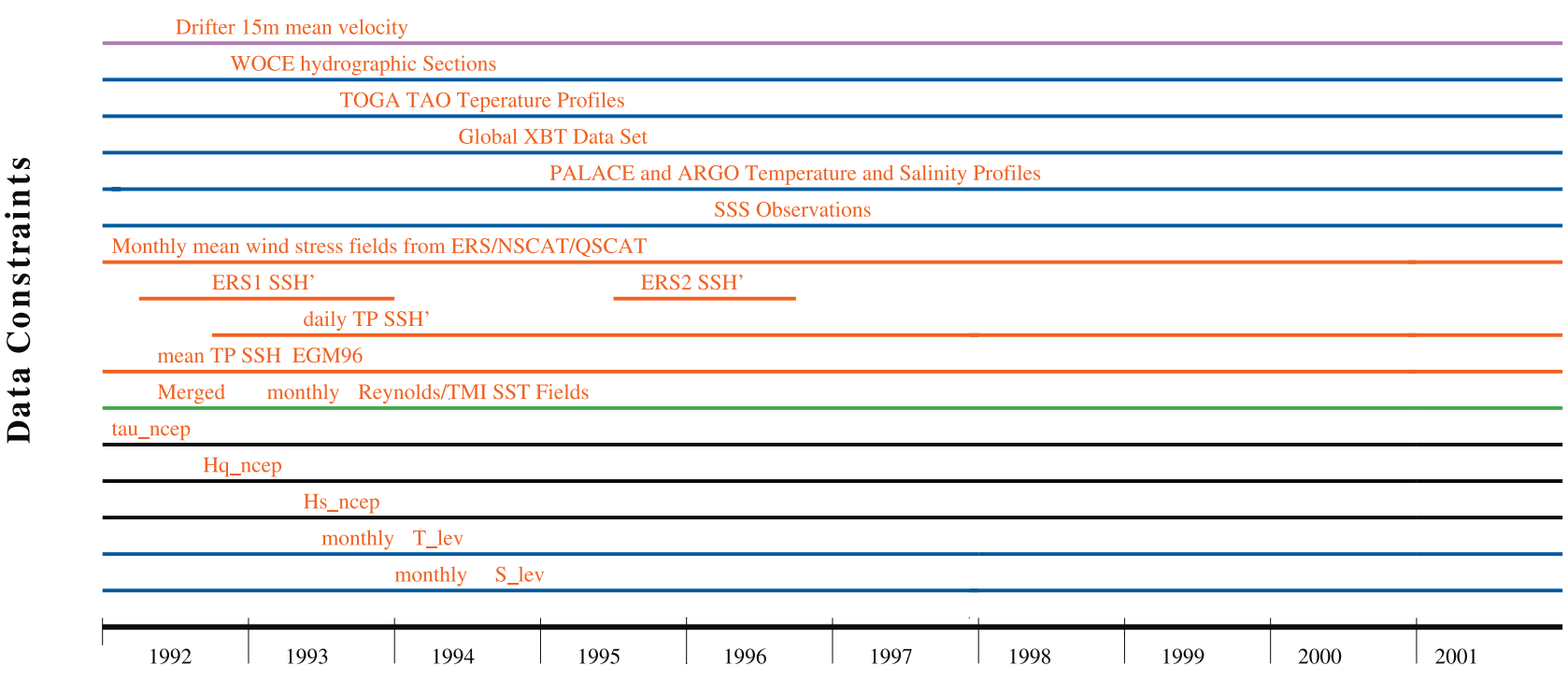

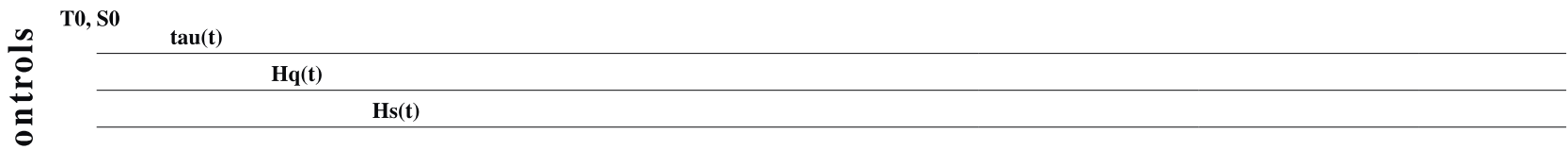

Figure 2. Schematic of the estimation calculation, 1992-2001. Data used as constraints are summarized in the top of the figure, with altimetric observations in red (ERS-1, ERS-2, and TOPEX/ Poseidon altimeter SSH anomalies and TOPEX/Poseidon mean SSH), the Reynolds and Smith [1994] and TMI [Wentz et al., 2000] sea surface temperature analysis (SST) in green, the surface boundary forcing data (stress, $\tau_{N C E P}$, heat flux, $H q_{N C E P}$, fresh water flux, $H s_{N C E P}$ ) from NCEP in black, and the WOCE, XBT, and ARGO in situ hydrography and the Levitus et al. [1994a, 1994b] climatologies of temperature $(T)$ and salinity $(S)$ in blue. Time-mean surface drifter data are shown in magenta. The lower part of the figure shows the elements of the control vector, which include the initial conditions on temperature and salinity $\left(T_{0}, S_{0}\right)$, daily $\tau$, and $H_{q}$ and $H_{s}$ fields.

[15] A schematic of the optimization is provided in Figure 2. An iterative procedure is used to reduce the model-data misfit, by sweeping backward and forward over the 10-year time span, systematically modifying the control vector, and employing the adjoint solution to evaluate the misfit sensitivities. (This procedure is the "adjoint" method, or the "method of Lagrange multipliers"). In the present calculation, the control vector includes the three-dimensional initial-condition potential temperature, $\theta$, and salinity, $S$, fields, as well as the daily surface forcing fields of net heat, net freshwater, and momentum fluxes over the full 10 years: those parameters where adjusted during the optimization so as to bring the model into consistency with ocean observations. (Although river run-off is not a control parameter, changes in net surface freshwater fluxes near coasts can compensate for erroneous discharge values.) Model uncertainties are assumed formally to reside entirely in the initial conditions and surface forcing fields (but residual misfits imply additional errors). We will test the consistency of these assumptions by showing that only relatively minor adjustments of the control vector are required to bring the model into consistency with the data.
[16] Stammer [2003] provided a first estimate (on a $2^{\circ}$ spatial grid) in which the control vector was extended to also include internal model errors in the horizontal and vertical tracer and momentum mixing coefficients. Results improved somewhat, especially in terms of long-term model changes. However, the surface flux fields changed only slightly from their values with fixed mixing coefficients, and we tentatively assume here that our results will be insensitive to mis-specification of internal parameters.

[17] Observations, to which the model was fit, are shown in the top part of Figure 2. They include several satellite data sets (see below), surface drifter velocities, in-situ hydrographic temperature, and salinity profiles as well as WOCE hydrographic sections. We also constrain the model's monthly mean climatology of temperature and salinity through the Levitus et al. [1994] climatology. Surface forcing fields are constrained through daily NCEP surface fluxes. A detailed summary of all data sets that are being used in the estimation and their prior error statistics is given by Lu et al. [2002]. It should be noted that the model drift in temperature and salinity was minimized over the entire period. Although small, regional drifts of the model sea surface height, temperature, and salinity fields are not 
eliminated altogether by this procedure, and we here analyze the remaining drift with the view that it probably represents real oceanic change.

\section{Adjusted Net Heat Flux}

\subsection{Global Fields}

[18] Consider first the geographic variations in the ECCO-estimated time-mean net surface heat flux field during 1992-2001 (Figure 3). Overall, the adjustments to NCEP (compare Figure 3c) have not altered the large-scale features, which remain generally consistent with both the ASOC fields and LY04 (Figure 4), as well as other climatologies (compare Figure 6). Specifically, there is a pronounced east-west asymmetry across ocean basins and a clear north-south symmetry about the equator. While maximum heat loss can be found over all western boundary currents, the heat uptake is enhanced along most of the eastern ocean boundaries with the continents, where the offshore Ekman transport upwells cold water from below. Australia is a notable exception, showing heat loss all around the continental margins. Most of the heat uptake of the global ocean occurs at low latitudes. Subtropical gyres tend to gain heat in their eastern parts (e.g., in the North and South Pacific). We note also the warming (of about $40 \mathrm{~W} / \mathrm{m}^{2}$ ) over Flemish Cap in the North Atlantic that is likewise present in the original NCEP fields as well as in the ASOC climatology and with LY04. In the Indian Ocean, the ECCO adjustments produce a heat uptake along all Northern Hemisphere western boundaries that is also seen in the ASOC climatology and with LY04 (although in the ASOC fields with larger amplitude), but is absent in the reanalysis heat flux. The loss of heat to the atmosphere in the subtropical Pacific and Atlantic Oceans between about $10^{\circ}$ and $20^{\circ}$ latitude is usual, and is now also visible in the ASOC climatology. A net heat loss can be found again farther poleward, with a maximum in the North Atlantic. We note that the stripes in the LY04 field on small spatial scale originate from the NCEP model fields (originating from the influence of mountain ranges such as the Andes) and as such are an artifact in the NCEP re-analysis results.

[19] Changes in mean net surface heat flux relative to the prior NCEP fields are shown in Figure 3c evaluated over the entire 10-year period. For a comparison, similar differences, but between LY04 and NCEP fluxes, are shown in Figure 3e from the period 1991 through 2000. Although not covering the identical period, adjustments made by ECCO, and those made by LY04 to the NCEP re-analysis, have striking similarities in their largescale patterns and amplitudes. This conclusion is true for all basins, but especially for the Indian Ocean where the adjustments in ECCO and LY04 are close to identical. Large regions in the ECCO adjustments show changes of $\pm 20 \mathrm{~W} / \mathrm{m}^{2}$, values that are entirely consistent with accepted uncertainties $[W G A S F, 2000]$ and the formal prior uncertainty in the net heat flux field [see $L u$ et al., 2002, Figure 7]. Over much of the same areas, LY04 show similar differences with NCEP, indicating their independent approach agrees in the tendencies of their required large-scale changes to the NCEP re-analysis-1. The overall RMS difference between our net surface heat flux field and the NCEP re-analysis-1 field is about $17 \mathrm{~W} / \mathrm{m}^{2}$.
This can be compared with a similar RMS difference, but relative to the NCEP re-analysis-2 net heat flux which is close to $26 \mathrm{~W} / \mathrm{m}^{2}$.

[20] Some of the large-scale similarities in ECCO and LY04 adjustments correspond to known problems with the re-analysis. Most notably, the lack of stratus clouds in the NCEP model over the eastern tropical Pacific and Atlantic has been identified as leading to an excess of short wave radiation into the ocean over those regions [Trenberth et al., 2001]. An eastern tropical Pacific feature appears in both ECCO and LY04 analysis as a region of large negative heat flux differences. The ECCO estimate reduces the net flux by $20-40 \mathrm{~W} / \mathrm{m}^{2}$. Note also that the optimization removes some of the small-scale Gibbs effects present in the initial NCEP net heat flux fields.

[21] Large-amplitude positive ECCO flux adjustments (i.e., increased input) occur, generally, over western boundary current regions, such as the Brazil/Falkland-Malvinas confluence, the Agulhas retroflection, the Kuroshio, and especially the Gulf Steam and its extension. Much of this later change has to be attributed to the model's failure to resolve the Gulf Stream due to its limited spatial resolution, where deviations between the ECCO changes and those from LY04 are largest. However, those large differences are limited primarily to the immediate vicinity of the path of the Gulf Stream. North and south of it, we again find reasonable agreement between the two estimates, even in the Labrador Sea where both fields indicate substantial reduction of mean cooling relative to NCEP estimates. Renfrew et al. [2002] found from direct air-sea flux measurements further evidence that the NCEP net surface heat fluxes overestimate the heat loss in the Labrador Sea.

\subsection{Zonal Integrals}

[22] Zonal averages of the net surface heat flux from ECCO are shown in Figure 5 for the global ocean and for individual basins, respectively, and can be compared with previous results from ECMWF [e.g., Garnier et al., 2000] and NCEP re-analysis products [Beranger et al., 1999; $W G A S F, 2000]$. In the present results, heat gain in the tropical Pacific and Atlantic have roughly the same amplitude per unit area; the Indian Ocean however, shows markedly reduced values. A common feature of heat flux climatologies is the pronounced warming of the Southern Ocean between about $40^{\circ} \mathrm{S}$ and $60^{\circ} \mathrm{S}$ (compare with Figure 6). This warming is located primarily over the Atlantic Ocean, exists with somewhat reduced amplitude over the Indian Ocean sectors, and is only weakly present over the Pacific sector of the Antarctic Circumpolar Current (ACC). A similar relative maximum heat flux over the Northern Hemisphere exists in roughly the same latitude range, where cooling rates become very small, actually becoming positive (heat gain) in the Pacific.

[23] The Northern Hemisphere north of $10^{\circ} \mathrm{N}$ loses heat to the atmosphere as does the Southern Hemisphere between $10^{\circ}$ and $40^{\circ} \mathrm{S}$ and south of $60^{\circ} \mathrm{S}$. Note also that heat loss by the ocean to the atmosphere in the Southern Hemisphere occurs to some extent in the South Pacific, but is most intense in the Indian Ocean. Much of the latter energy must be imported from the Pacific through the Indonesian Throughflow or the Southern Ocean (compare also Stammer et al. [2003]). The Atlantic shows a positive heat gain around 

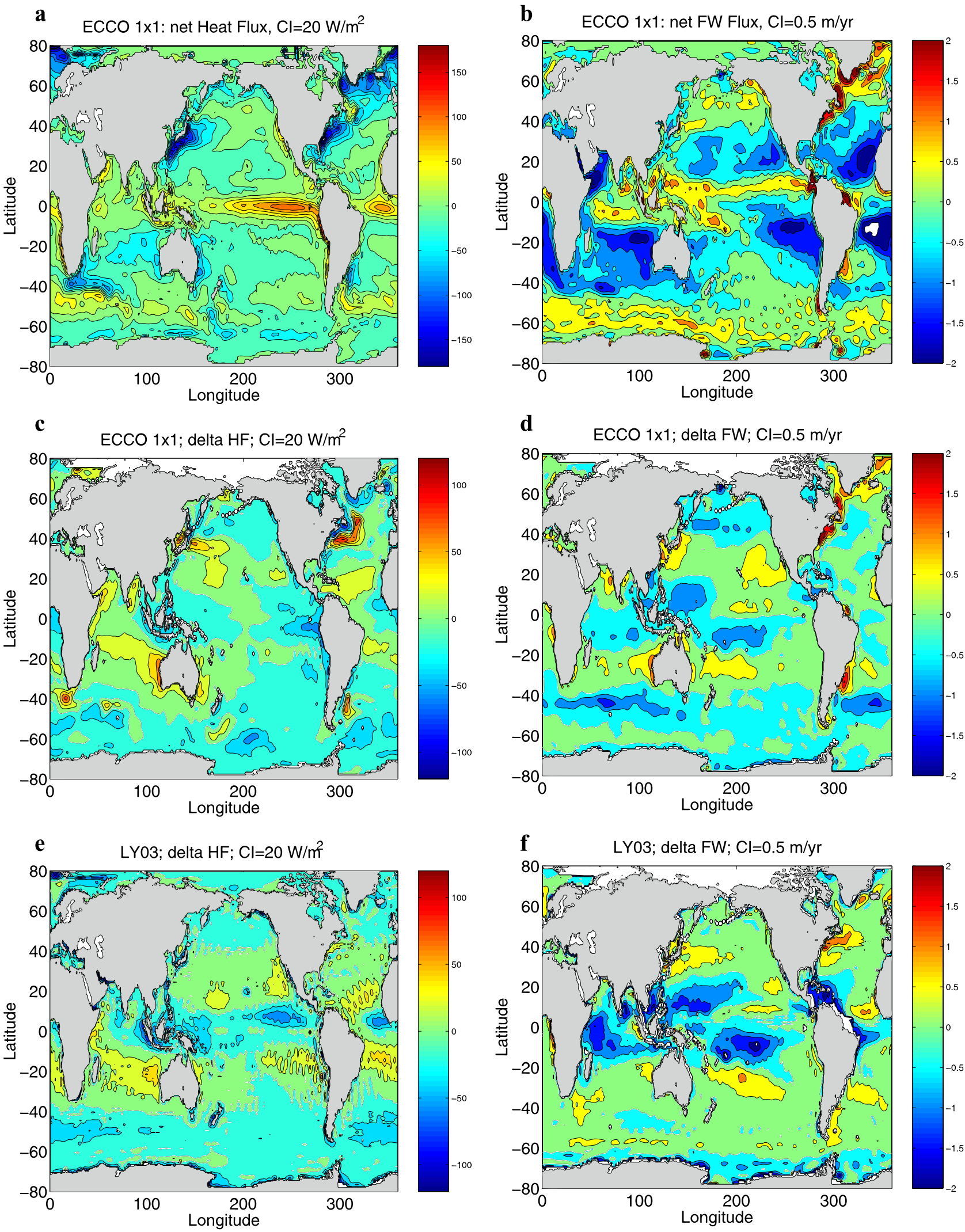

Figure 3. The mean net (a) surface heat and (b) freshwater flux fields to/from the atmosphere as they result from the optimization over the period 1992 through 2001. Mean changes in (c) net surface heat exchange relative to the prior NCEP fields estimated over the same period (in $\mathrm{W} / \mathrm{m}^{2}$, and (d) the net freshwater exchange (in $\mathrm{W} / \mathrm{m}^{2}$ ). Mean difference LY04 - NCEP from the period 1991-2000 (e) for net surface heat flux and (f) for fresh water flux. In all panels, positive values are into the ocean. The white lines in the lower two rows of the figure are the zero contour lines. 
a Annual mean net heat flux - Adjusted SOC (Grist and Josey, 2003)
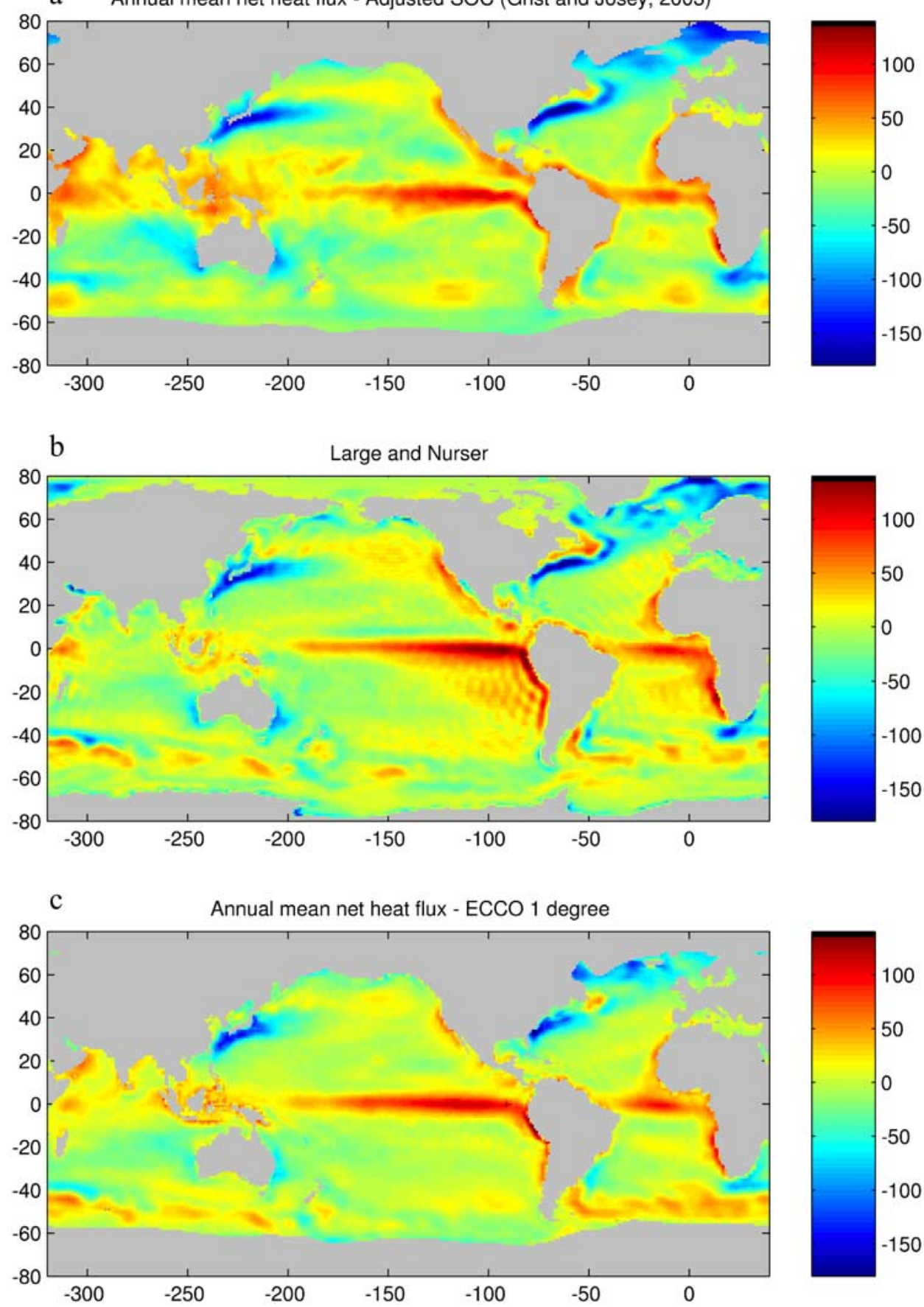

Figure 4. Global maps of the annual mean net adjusted SOC surface heat flux (a) from Grist and Josey [2003], (b) from LY04, and (c) from the ECCO $1^{\circ}$ solution (similar to Figure 3a).

$20^{\circ} \mathrm{S}$ like NCEP, but contrary to some other estimates [e.g., Trenberth and Caron, 2001; Brydan and Imawaki, 2001; W. G. Large and S. Yeager, personal communication, 2004]. [24] Figure 6 shows the globally averaged zonal mean net heat flux for various surface flux climatologies. The ECCO $1^{\circ}$ field clearly lies in the middle of the range spanned by other recent climatologies over virtually the full latitude range. We note that the ECCO result is almost identical with that obtained by Trenberth and Caron [2001] over the Southern Hemisphere but is inconsistent in the tropics and Northern Hemisphere around $40^{\circ} \mathrm{N}$, where the Trenberth and Caron [2001] estimates are most extreme. By comparison, the previous $2^{\circ}$-ECCO field [Stammer et al., 2002] is clearly biased toward zero, particularly near $30^{\circ} \mathrm{N}$. Improved resolution and an enlarged data base together contribute to the improvement in the new $1^{\circ}$ solution.

[25] It is important to note that the horizontal transports computed directly from the model state do not agree in detail with those implied by the adjusted surface heat fluxes. To illustrate this important point we show in Figure 7a the horizontal transports as they follow directly from the model fields together with those inferred from integrating the 

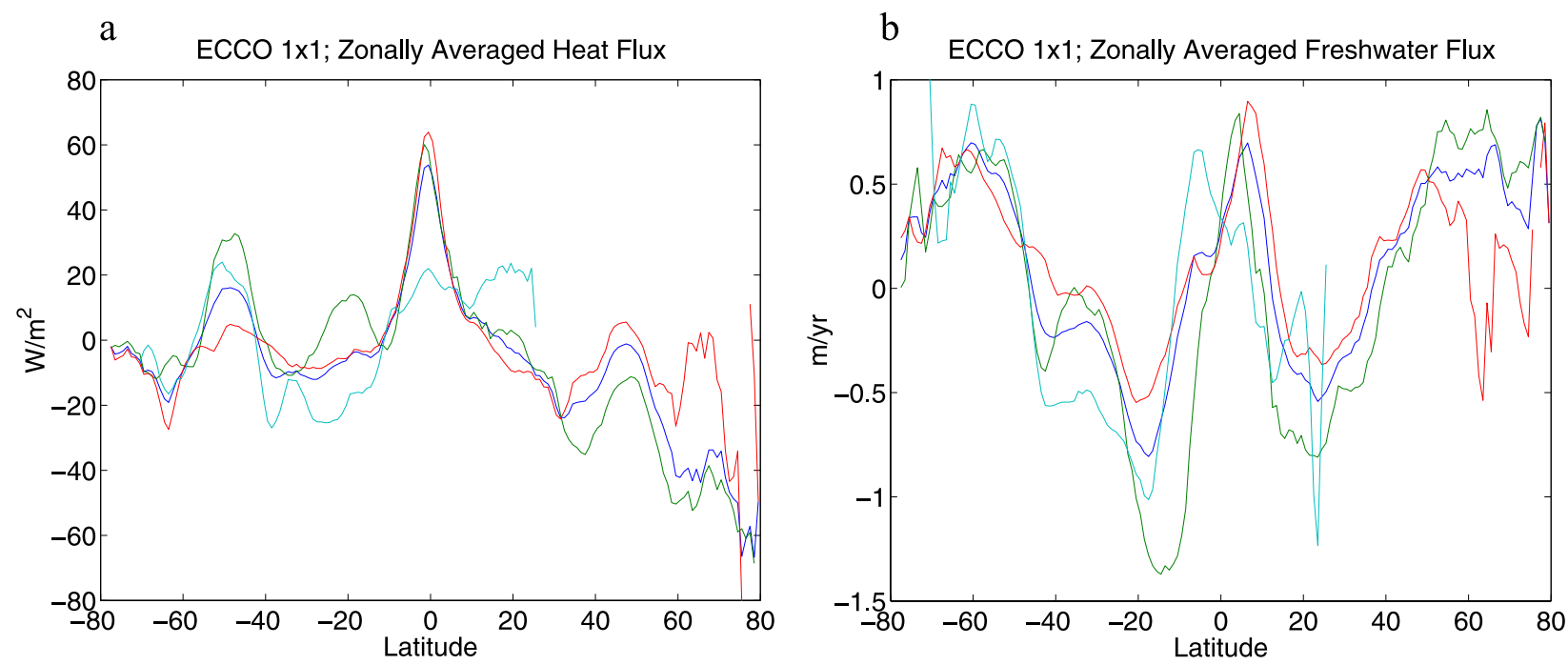

Figure 5. Zonally integrated (a) heat and (b) surface fresh water fluxes, evaluated globally (blue curves) and over the Atlantic, Pacific, and Indian Ocean sectors (green, red, and cyan, respectively).

actual surface heat fluxes first zonally across each ocean basin and then meridionally, starting from the south. The transport curves deviate, and suggest errors in ocean heat transport estimates from surface fluxes of the order of $0.4-$ $5 \mathrm{PW}$. The differences are due to a net heat uptake of the model by close to $1.18 \mathrm{~W} / \mathrm{m}^{2}$. We note that our ocean transports approximately agree with those of Ganachaud and Wunsch [2003], obtained from a box-inversion of hydrographic WOCE sections.
[26] The conflict between the two curves is an indication that the local heat storage term in the model is significant. Over short integration times, changes in local heat storage are expected, owing to the slow adjustment processes in the model. However, a significant fraction of the changes are physically realistic and manifested as long-term changes in the ocean observations [e.g., Levitus et al., 2001]. It is therefore not correct to assume, as is often done in studies inferring the ocean transport from atmospheric fluxes, that

Zonally averaged annual mean net heat flux - various climatologies

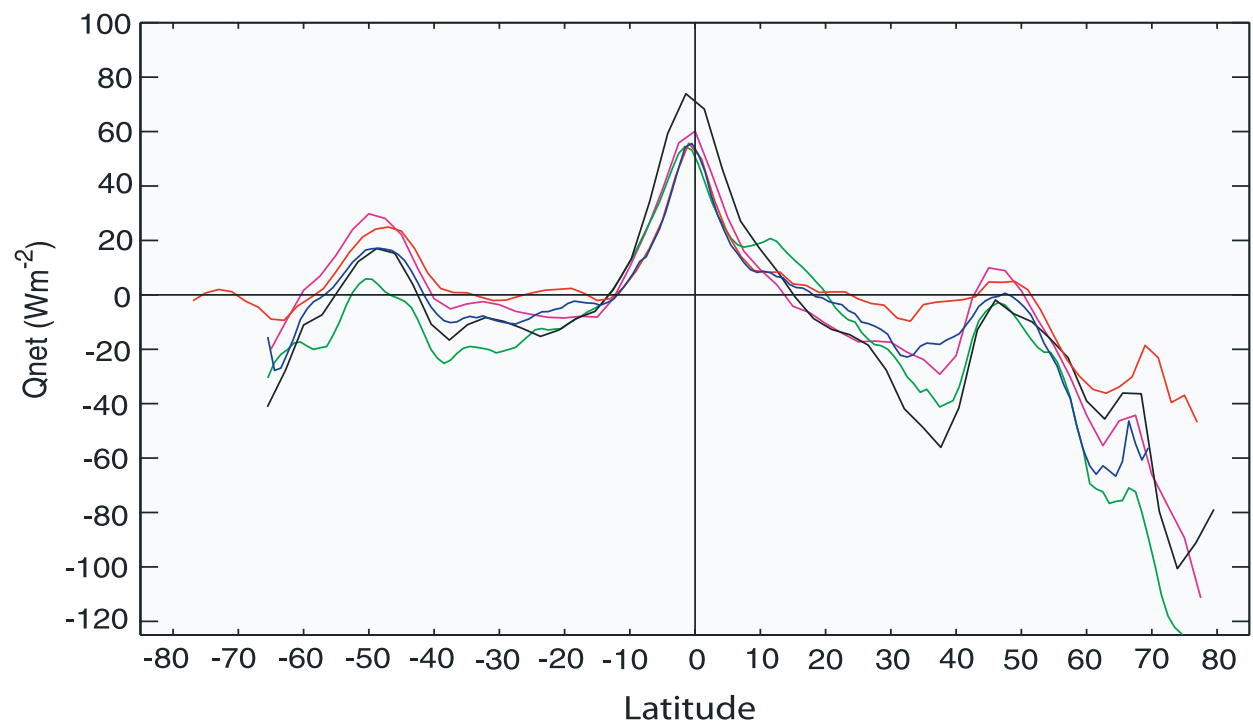

Green-Adjusted SOC (Grist and Josey, 2003); Blue-ECCO 1 deg; Red-ECCO 2 deg Black-Trenberth residual; Magenta-NCEP reanalysis

Figure 6. Globally averaged zonal mean net heat flux for various data sets, including the adjusted SOC climatology (green), the Trenberth et al. [2001] estimate (black) and the NCEP net heat flux (magenta). The ECCO $1^{\circ}$ fields (blue line) lie in the middle of the range spanned by other recent climatologies over virtually the full latitude range. By comparison the old $2^{\circ}$ fields (red line) are biased toward zero, particularly at around $30^{\circ} \mathrm{N}$. 


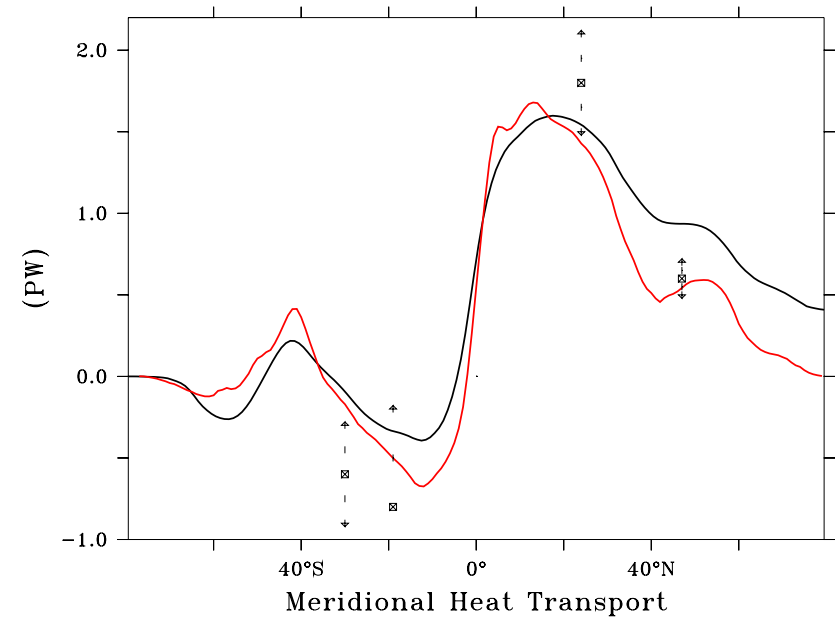

$\mathrm{b}$

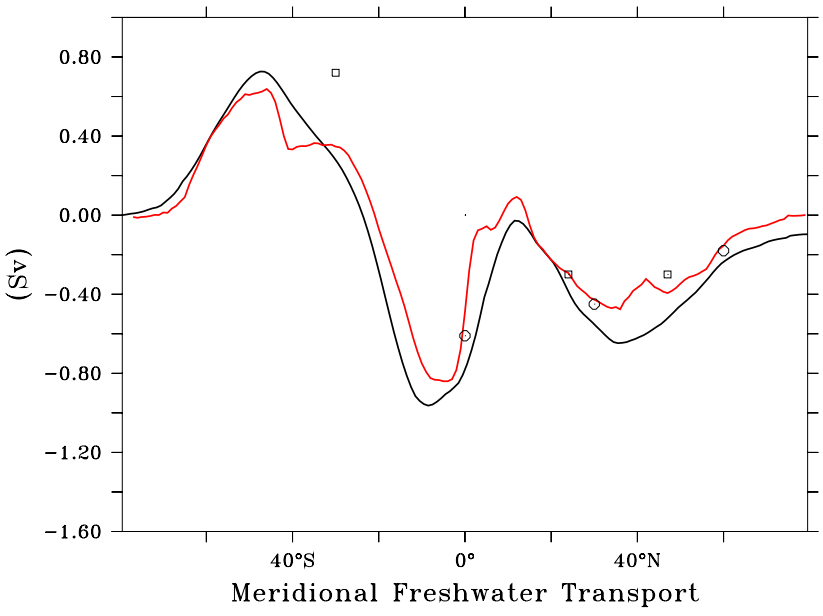

Figure 7. Meridional (a) heat and (b) freshwater transports, as computed directly from the model flow and tracer fields (red curve) and as inferred from integrated surface heat and freshwater fluxes (black curves). Differences corresponding to a surface neat heat flux are $1.18 \mathrm{~W} / \mathrm{m}^{2}$ and $-0.020 \mathrm{~m} / \mathrm{yr}$ for fresh water flux and represent a non-zero storage term of heat and freshwater in the model. The squares in Figure 6a represent estimates of Ganachaud and Wunsch [2003] for heat transports, and the symbols in Figure 6b represent estimates of Macdonald and Wunsch [1996] (squares) and Wijffels et al. [1992] (circles), for fresh water transports.

net heat fluxes balance globally on all timescales. An alternative interpretation of the figure is that horizontal heat transport shows a poleward heat flux of $0.4 \mathrm{PW}$ across $80^{\circ} \mathrm{N}$ into the Arctic.

\subsection{Regional Evaluations}

[27] A detailed comparison of net surface heat fluxes as they result from NCEP, the adjusted SOC flux data set [Josey et al., 1999], and $1^{\circ}$ ECCO results is provided in Table 1 for the Gulf Stream region $\left(30^{\circ} \mathrm{N}-50^{\circ} \mathrm{N}, 80^{\circ} \mathrm{W}-\right.$ $\left.50^{\circ} \mathrm{W}\right)$, and the Kuroshio $\left(24^{\circ} \mathrm{N}-36^{\circ} \mathrm{N}, 124^{\circ} \mathrm{E}-150^{\circ} \mathrm{E}\right)$. Also included for comparison are the results from the previous $2^{\circ}$ ECCO estimate. Over the Kuroshio, the first three estimates agree within $\pm 5 \mathrm{~W} / \mathrm{m}^{2}$. While SOC and ECCO values are indistinguishable, NCEP estimates appear to provide about $10 \mathrm{~W} / \mathrm{m}^{2}$ less cooling. Over the Gulf Stream the ECCO and NCEP results provide about $10 \mathrm{~W} / \mathrm{m}^{2}$ less cooling than SOC. In contrast, the previous $2^{\circ}$ solution was biased low by $35 \mathrm{~W} / \mathrm{m}^{2}$ and $25 \mathrm{~W} / \mathrm{m}^{2}$ over the Gulf Stream and Kuroshio, respectively.

[28] Also included in Table 1 are results from the Subduction Experiment region in the eastern subtropical Atlantic. Measurements from the northeast mooring of the flux reference buoy array at $33^{\circ} \mathrm{N}, 22^{\circ} \mathrm{W}$ available from the period January 1992 through June 1993 (see Moyer and Weller [1997] for details), lead to a mean net heat flux into the ocean of $25 \mathrm{~W} / \mathrm{m}^{2}$ there. Corresponding ECCO estimates during the same period are $2 \mathrm{~W} / \mathrm{m}^{2}$ as compared to an NCEP value of $-8 \mathrm{~W} / \mathrm{m}^{2}$; that is, the estimation procedure reduced the apparent NCEP bias by about than $10 \mathrm{~W} / \mathrm{m}^{2}$. In comparison, ASOC fluxes result in $-5 \mathrm{~W} / \mathrm{m}^{2}$ at the same location.

[29] ECCO $1^{\circ}$ surface heat fluxes agree approximately with SOC not only in their time-mean, but also in their seasonal cycle. This is demonstrated in Figure 8, showing a comparison of the seasonal cycle of the $1^{\circ}$ ECCO fluxes with the ASOC climatology and NCEP fields. The time series of all three data sets show good agreement over the Kuroshio and the Gulf Stream: Their monthly mean net heat exchanges are again indistinguishable within an assumed $20 \mathrm{~W} / \mathrm{m}^{2}$ uncertainty (no complete error estimate is available for any of the three fields). The standard deviation of the difference between ECCO and ASOC monthly values is $12 \mathrm{~W} / \mathrm{m}^{2}$ for the Gulf Stream and $24 \mathrm{~W} / \mathrm{m}^{2}$ for the Kuroshio; for the difference NCEP-ASOC, the corresponding values are $17 \mathrm{~W} / \mathrm{m}^{2}$ and $23 \mathrm{~W} / \mathrm{m}^{2}$, respectively. It is noteworthy that over the Gulf Stream, between January and March, NCEP and ECCO estimates show less heat loss to the atmosphere than do the ASOC fields. In subsequent months, however, they are quite similar, indicating that the overall biases noted in Table 1 for the Gulf Stream region result primarily from winter months. For the Kuroshio, NCEP and ECCO estimates show less cooling during the months January through March and during October through December, while

Table 1. Net Surface Heat Flux (in $\mathrm{W} / \mathrm{m}^{2}$ ) Over the Gulf Stream $\left(30^{\circ} \mathrm{N}-50^{\circ} \mathrm{N}, 80^{\circ} \mathrm{W}-50^{\circ} \mathrm{W}\right)$ and Kuroshio $\left(30^{\circ} \mathrm{N}-40^{\circ} \mathrm{N}, 140^{\circ} \mathrm{E}-\right.$ $180^{\circ} \mathrm{E}$ ) and Near $33^{\circ} \mathrm{N}, 22^{\circ} \mathrm{W}$, as They Result From the Northeast Mooring ${ }^{\mathrm{a}}$

\begin{tabular}{lccc}
\hline Data Set & Gulf Stream & Kuroshio & Subduction \\
\hline Weller & & & 24 \\
NCEP & -60 & -66 & -8 \\
ASOC & -67 & -76 & -5 \\
ECCO & -57 & -72 & 2 \\
ECCO 2 & -28 & -48 & 15 \\
\hline
\end{tabular}

${ }^{\mathrm{a}}$ From the Subduction Surface Buoy Measurements Array [Moyer and Weller, 1997], the NCEP Re-analysis, the Adjusted Southampton Oceanography Centre (ASOC) Flux Data Set [Grist and Josey, 2003], and the ECCO estimates. Positive values are into the ocean. Also shown are numbers from the previous ECCO estimate on a $2^{\circ}$ spatial grid [Stammer et al., 2002]. 

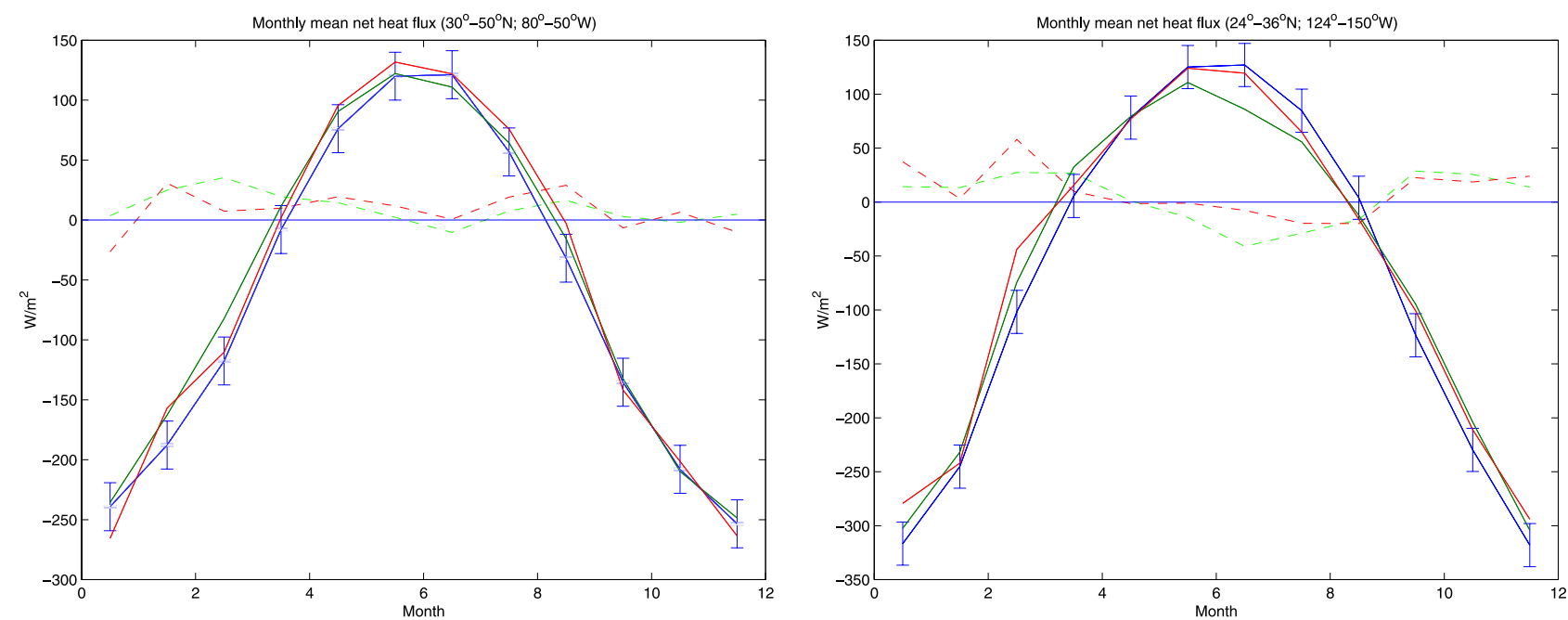

Figure 8. Comparison of the seasonal cycle of the $1^{\circ}$ ECCO fluxes (green) with the adjusted SOC climatology (blue, from [Grist and Josey, 2003]) over the Gulf Stream and Kuroshio regions. Also shown for a comparison are the results from the NCEP re-analysis (red). The error bars indicate a hypothetical uncertainty of $\pm 20 \mathrm{~W} / \mathrm{m}^{2}$ in the ASOC fields. Dashed lines are differences between ECCO and ASOC (green) and between NCEP and ASOC (red).

during the remaining 6 months they show less warming, with an overall zero bias.

\section{Adjusted Fresh Water Flux}

[30] Estimates of the surface net fresh water fluxes as they emerge during 1992-2001 are shown in Figure 3b. The expected large-scale features are evident, and again we can find a clear east-west basin asymmetry, and a pronounced symmetry in the meridional direction. However, the symmetry is now relative to the ITCZ and not (as is the case for heat flux) relative to the equator.

[31] Negative net freshwater flux into the ocean, i.e., positive evaporation minus precipitation, $E-P$, is present over the eastern side of all subtropical gyres, and the Arabian Sea. Losses are quite similar in pattern between Atlantic, Pacific, and Indian Ocean, although the Indian Ocean shows enhanced evaporation around $40^{\circ} \mathrm{S}$. The salinity maximum in the North Atlantic and its origin in the strong freshwater loss over the eastern subtropical Atlantic is well known. Here a similar effect appears in all subtropical gyres.

[32] Large net precipitation is found in the tropical convergence zones, including the western Pacific warm pool, over the midlatitude storm tracks, and along the Antarctic Circumpolar Current (ACC). Largest freshwater input occurs near the boundaries, and could be associated with incorrect river discharge estimates (e.g., in the Amazon delta or off the Rio de la Plata mouth) or with ice import and melting (e.g., over parts of the Labrador Sea and around Greenland). The latter process is not properly represented in the present ECCO model, but future calculations will include ice simulations explicitly. The estimation procedure attempts, necessarily, to enhance net freshwater fluxes from the atmosphere over those regions.

[33] Differences between ECCO-estimated freshwater fluxes minus NCEP estimates and LY04 minus NCEP estimates are shown in Figures $3 \mathrm{c}$ and $3 \mathrm{f}$, respectively. As with the heat fluxes, there are clear similarities between both difference fields, especially over the Pacific and Indian Oceans. More evaporation, i.e., net fresh water loss, is required by ECCO and LY04 estimates over the western tropical Pacific, the tropical Indian Ocean, the western tropical Atlantic, and the subpolar North Pacific. By contrast, an increased net input of freshwater is required over the eastern tropical Pacific, large parts of the subtropical gyres, and western boundary currents, especially the Kuroshio. In the LY04 values, some of those changes are more pronounced (e.g., in the tropical Pacific) and reach farther across the basins than they do in the ECCO results, but they are clearly present in the latter estimates as well.

[34] Zonally averaged fresh water flux estimates are shown in Figure 5b. Global and basin integrals are positive at low latitudes. However, maxima are shifted in their geographic position between basins: The Pacific Ocean has the maximum at around $5^{\circ} \mathrm{N}$, while the Indian Ocean gains most freshwater at about $5^{\circ} \mathrm{S}$. A gain in freshwater occurs also over high latitudes. Over the Southern Ocean, the gain is equally distributed over all three basin sectors. In the Northern Hemisphere, maximum precipitation can be found in the Atlantic Ocean. Although all subtropical regions lose freshwater, the largest loss occurs over the southern Indian Ocean.

[35] Horizontal freshwater transports computed from surface fluxes or from ocean transports again do not agree owing to the presence of a significant storage in salt or freshwater. Figure $7 \mathrm{~b}$ shows estimates of horizontal transports of freshwater as they were inferred from integrating the actual surface freshwater fluxes, and as they have been computed from the horizontal transports. Estimates of the ocean freshwater transports agree with those from Macdonald and Wunsch [1996] and Wijffels et al. [1992]. Differences between the curves are due to a global net 
evaporation of $0.02 \mathrm{~m} / \mathrm{yr}$. As it stands, Figure $7 \mathrm{~b}$ suggests a net influx of freshwater of close to $0.1 \mathrm{~Sv}$ from the Arctic into the general circulation. Determining how much of the estimated structure in the net surface freshwater fluxes is physically realistic depends fundamentally on an understanding of changes in atmospheric moisture content, water storage over land, ice melting, and import of ice from the Arctic into the North Atlantic. All such quantities are subject to significant change and uncertainty. From Figure 7, ocean state estimation appears as a plausible approach to testing knowledge of the global water cycle. (For a further discussion, see Wijffels [2001] and Ganachaud and Wunsch [2003].)

\section{Wind Stress Changes}

\subsection{Time Mean Wind Stress Fields}

[36] Adjusted wind stress fields are shown in Figure 9. Time-mean adjustments relative to the NCEP first guess are also shown, as are the differences between the mean wind stress components obtained from the ERS1/2, NSCAT, and QSCAT measurements for 1992 through 2001, and the NCEP fields. For the latter comparison, ERS-1/2 gridded monthly wind stress fields on a global $1^{\circ}$ by $1^{\circ}$ grid [Bentamy et al., 1998; IFREMER, 2000] are used. We note that the QSCAT-NCEP difference fields are very similar to those between NSCAT and NCEP described by Milliff et al. [1999].

[37] A substantial fine structure is visible in the ECCO adjustments to NCEP first guess fields. To some extent, this result is an expression of the fact that no spatial error covariance structure was imposed on the wind stress changes. That the relatively largest wind stress modifications exist close to intense boundary current systems also indicates the difficulties this $1^{\circ}$ horizontal resolution model has in producing the proper current separation without extra vorticity input by the modified wind stress. We note, however, that even these large changes in the wind stress are all within the prior error bounds of the NCEP wind stress fields provided by $\mathrm{Lu}$ et al. [2002], and which were based upon QSCAT scatterometer measurements.

[38] The latter problem of boundary current separation is common to many numerical models. Chelton et al. [2004] describe recent advances in estimating scatterometer wind stress fields and report changes in the wind stress curl across the Gulf Stream which show similarities to what we report here in that significant differences are being observed in wind stress and wind stress curl across the Gulf Stream as compared to NCEP which have their origin in differences in the stability of the atmospheric boundary layer over cold and warm water.

[39] On the large scale and outside the boundary current regions, ECCO wind stress changes, such as the increased values associated with trade winds over the tropical Pacific, are entirely consistent with prior knowledge of NCEP reanalysis shortcomings [e.g., Milliff et al., 1999]. These adjustments may therefore well be true corrections to the NCEP fields. The satellite observations likewise point toward wind stress being too strong in the midlatitude NCEP re-analysis. Both westerly and easterly winds from ECCO and the satellites tend to be weaker than in the NCEP fields outside the tropical regime. An exception can be found in the region to the west of Drake Passage where strengthened zonal stresses occur.

[40] In terms of meridional stress changes, scatterometer data indicate a smaller poleward component at latitudes higher than about $30^{\circ}$. We find somewhat similar tendencies in the ECCO estimates. In particular, we find similarities in the changes along the west coast of America and Africa: There the changes in both fields relative to NCEP are positive in the eastern tropical Pacific and along the California current; they are negative along the Bengal current and along the coast of South America.

[41] Over most of the ocean, the dynamically relevant forcing is the wind stress curl. We therefore compare in Figure 10 the differences in mean wind stress curl as they emerge from ECCO estimates minus the NCEP ones, and those from and ERS minus NCEP fields. The comparison is limited to large scales over the lower latitudes where we have seen some skill in the ECCO estimates in improving NCEP stress estimates. As is to be expected, differences in the curl adjustments can be found in the vicinity of strong boundary currents, for example, the Kuroshio, where internal model errors (e.g., lack of resolution) possibly dominate the wind stress adjustments. Note also the reversal of the dipole structure around Hawaii between the two fields. Nevertheless, some agreement in the curl adjustments is obvious, and includes bands of positive and negative curl changes that extend zonally across the Pacific. Even some regional changes are similar, such as the positive anomaly in the eastern South Pacific, the tropical Atlantic, and the Indian Ocean. In a recent study, Kessler et al. [2003] showed further evidence of zonal-bandedness in wind stress curl as seen by the scatterometer data, and apparently resulting in improved simulation of the tropical Pacific flow field. Although they use a model with higher spatial resolution, they reach the same conclusion as drawn here: changes imposed by the ECCO and scatterometer estimates are improvements in wind products. That ECCO adjustments are larger than what is being measured by the scatterometer may be an indication of the inadequate spatial resolution of the model for simulating the low-latitude circulation.

\subsection{Time-Varying Wind Stress}

[42] State estimation adjusts the surface forcing on a day-to-day basis (the current estimate adjusted 2-day averaged surface fluxes), and ultimately, as model physics and observations improve, time-varying weather events may also become correctable. To provide some insight into the time-varying signal, we show in Figure 11a a comparison of the zonal wind stress component measured at $170^{\circ} \mathrm{W}$ on the equator by one of the Tropical Ocean Global Atmosphere-Tropical-Atmosphere-Ocean (TOGATAO) buoys [McPhaden et al., 1998] with nearby NCEP and ECCO estimates.

[43] To convert the TAO wind measurements into stress, observed winds at a normal height of $4 \mathrm{~m}$ above the sea surface were converted to winds at a $10-\mathrm{m}$-level reference height using the logarithmic wind profile equation. The observed parameters used in the subsequent calculation of the TAO wind stress are air temperature and relative humidity and their measurement heights, SST, and its measurement depth, and surface pressure. Details of the algorithm are provided by Fairall et al. [1996a, 1996b]; it 

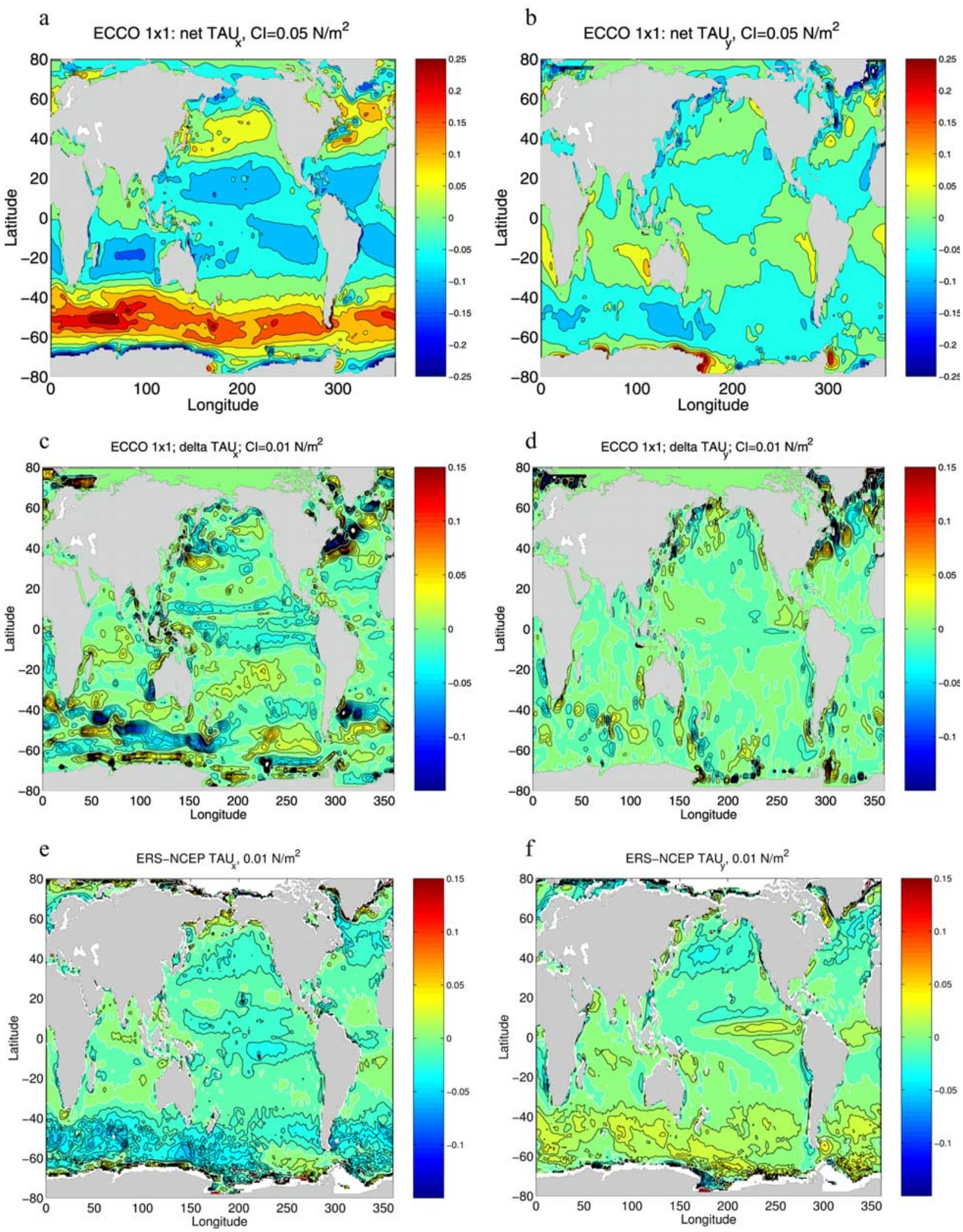

Figure 9. Mean (a) surface zonal wind stress and (b) meridional wind stress fields as they result from the optimization over the period 1992 through 2001 (in $\mathrm{N} / \mathrm{m}^{2}$ ). (c) Mean changes in ECCO meridional wind stress relative to the prior NCEP fields estimated over the six-year period 1992-2001 (in N/m²), and (d) for the meridional component (in N/ $\mathrm{m}^{2}$ ). (e) Mean difference in ERS zonal wind stress from 1992 through 1997 minus net NCEP surface heat fluxes from the same period. (f) The same as Figure 9e, but for the meridional stress. Positive values are eastward and northward, for zonal and meridional components, respectively. The white lines in the lower two rows of the figure are the zero contour. 

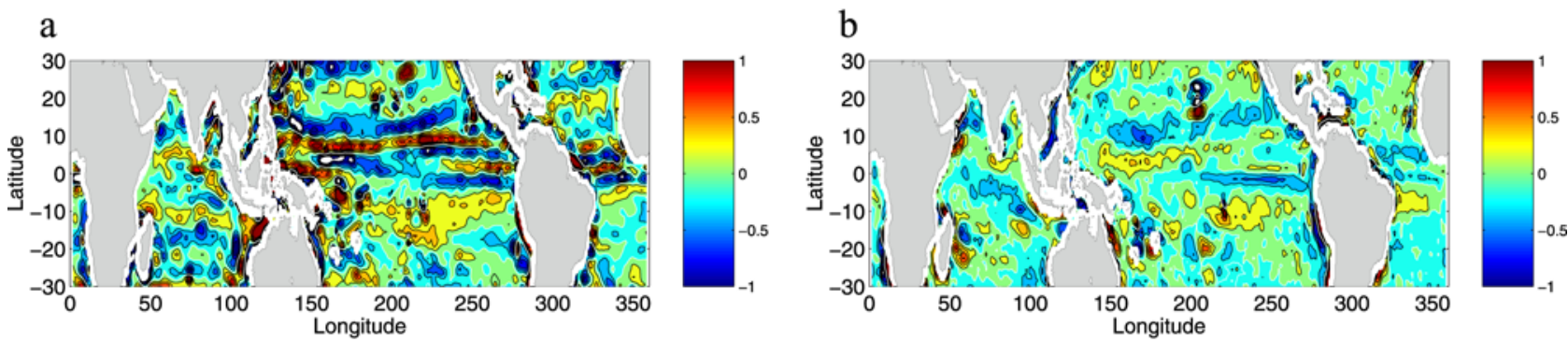

Figure 10. (a) Differences in wind stress curl estimated from mean ECCO $1^{\circ}$ wind stress fields minus those computed from NCEP and (b) the similar differences but between the ERS $1 / 2$ wind stress curl fields and NCEP for the period 1992 through 2001. Units are $10^{-7} \mathrm{~N} / \mathrm{m}^{3}$. The white lines are zero contour lines.
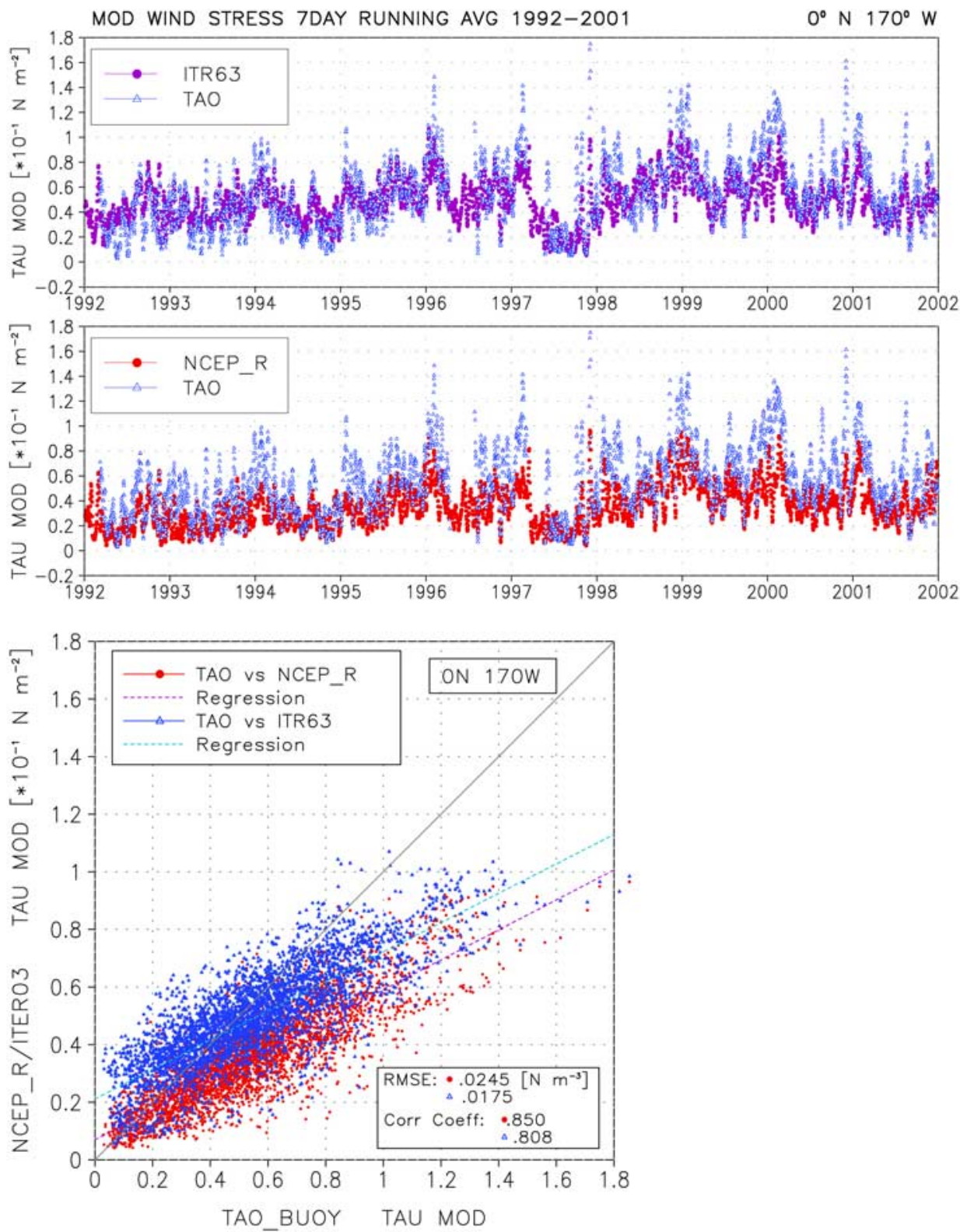

Figure 11. Comparison of ECCO and NCEP wind stress fields with TOGA TAO measurements at $170^{\circ} \mathrm{W}$ on the equator. (top) A time series of zonal TAO wind stress components (blue) and ECCO $1^{\circ}$ results (purple). (middle) A similar plot, but with NCEP fields in red. (bottom) Scatter diagrams of NCEP (red) and ECCO (blue) wind magnitude measurement at the same position against the TAO data. 


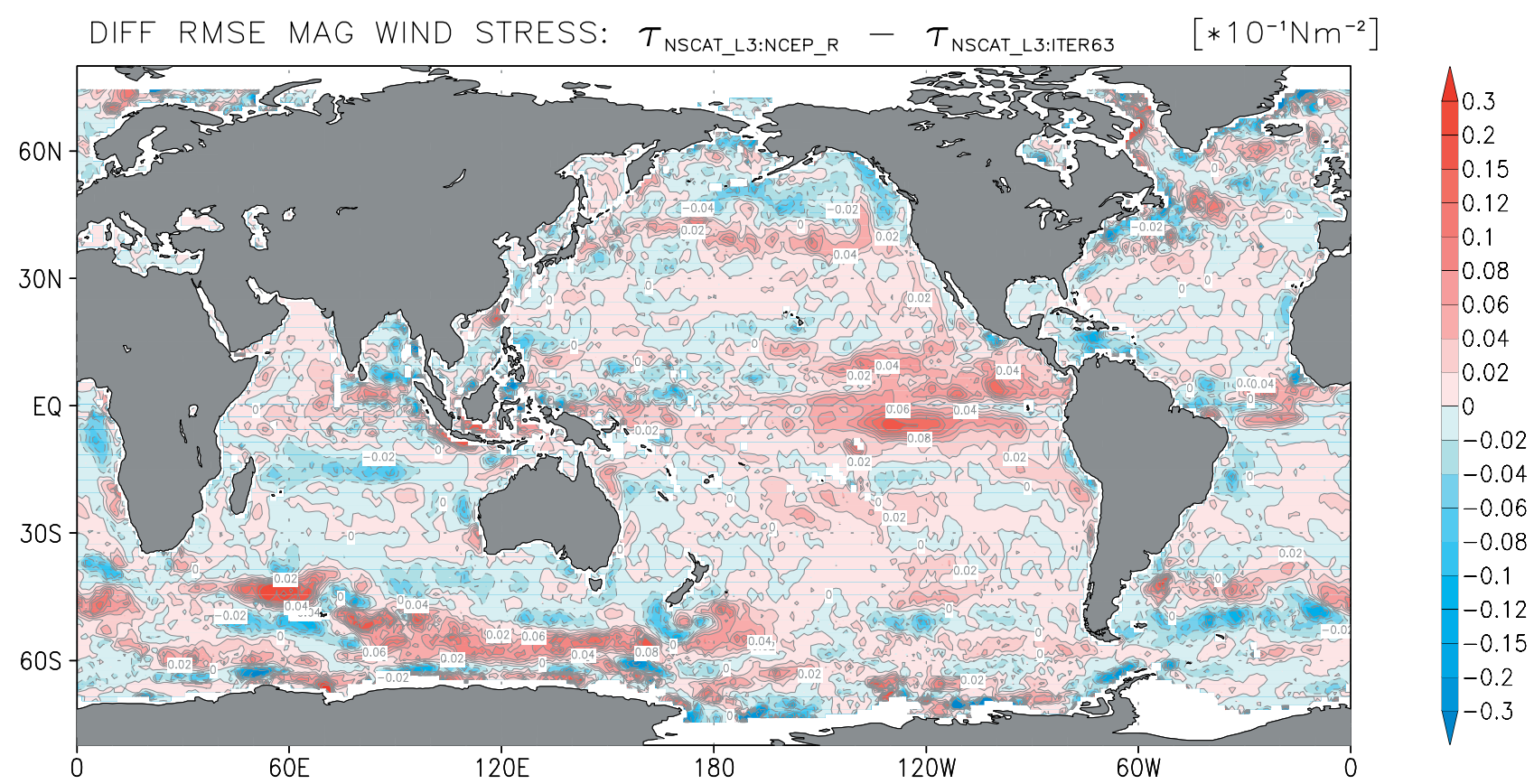

Figure 12. Reduction in the RMS difference between ECCO and NSCAT wind stress time series as compared to the original NCEP-NSCAT differences. Positive values indicate a respective misfit reduction (in $\mathrm{N} / \mathrm{m}^{2}$ ).

was designed to produce estimates of the turbulent fluxes of sensible and latent heat and the stress from inputs of bulk variables. Bulk transfer coefficients are based on the Liu et al. [1979] model with some modifications.

[44] A clear improvement in the ECCO estimates relative to the NCEP first guess is obvious, indicating that the estimation at this location brings both time series into better agreement with the TAO measurements by reducing an obvious bias in NCEP estimates. The RMS difference between the ECCO estimates and the TAO measurements reduces from $0.24 \mathrm{~N} / \mathrm{m}^{2}$ to $0.17 \mathrm{~N} / \mathrm{m}^{2}$; at the same time the correlation decreases slightly from 0.85 to 0.81 . A scatterplot of the ECCO wind stress magnitudes relative to TAO (not shown) is shifted upward toward the $45^{\circ}$ line to remove the overall bias, although the slope of a LS-line did not increase. Similar results are found for the entire equatorial region covered by TAO buoys.

[45] For a better understanding of the temporal signals in the ECCO adjustments off the equator, fields from NSCAT are used for comparison. To do so, daily NSCAT wind stresses were computed by using the level 3 wind vectors available from the Jet Propulsion Laboratory, at a reference height of $10 \mathrm{~m}$ on a rectangular, uniform, $0.5^{\circ} \times 0.5^{\circ}$ latitude-longitude grid covering latitude range $\pm 75^{\circ}$. A running 7-day filter was applied to both ECCO and scatterometer fields to remove shorter-period fluctuations.

[46] Figure 12 shows a summary of the comparison in form of a map of the improvement in the RMS difference between NCEP and NSCAT and between ECCO and NSCAT fields. Positive values indicate an improvement of the RMS misfit when going from NCEP to ECCO stress fields. Improvements exist over most of the tropical Pacific $\left( \pm 20^{\circ}\right)$, parts of the Arabian Sea, much of the midlatitude North Pacific, and parts of the ACC. Results for much of the subpolar North Pacific, the North Atlantic, the South Indian Ocean, and parts of the ACC appear to become degraded, however. The significant improvement of this figure as compared to the results from the previous $2^{\circ}$ resolution optimization can be understood in terms of better resolution, but also through the incorporation of additional scatterometer wind stress data.

\section{Discussion}

[47] Oceanic state estimation has advanced sufficiently to the point that it is now possible to make estimates of the atmospheric forcing fields required to reproduce the observed global ocean circulation. In the example discussed here, adjustments made to NCEP-re-analysis fluxes of momentum, heat, and fresh water through a global-scale, decade-long state estimate by the ECCO Consortium have been compared to independent estimates (LY04, SOC) made more directly. General agreement is found between the ECCO adjustments to the NCEP fields and those derived independently. In general, all inferred ECCO-shifts to NCEP values are within plausible, qualitative error estimates of the NCEP products. This appears to be the case especially for heat and freshwater flux fields that show an intriguing agreement with independent adjustments of NCEP fields in their large-scale structures and amplitudes. It seems to be also true for large-scale wind stress changes. However, wind stress changes show substantial small-scale structures most simply explained as owing to ocean model error, primarily resolution near boundaries, but also due to the lack of proper error covariance information provided to the estimation procedure. Nevertheless, we have obtained already here a solution that is basically consistent with our crude assumption that most uncertainties do reside in the 
initial conditions of the model and the surface forcing fields. Surface heat and freshwater fluxes likewise show also enhanced anomalies over western boundary currents where the reduced skill in simulating the correct boundary current strength (due to limited resolution) leads to unrealistic horizontal heat transport and transport divergences. As mentioned in the text, however, those anomalies seem to be limited to the direct vicinity of the boundary currents and we do see no indication that the corrections in surface fluxes estimated over the large-scale interior ocean are significantly affected through those shortcomings, which will be remedies in future high-resolution approaches.

[48] Improvements in the ECCO-procedure will be forthcoming. These include the use of spatial covariances of the flux field errors, as well as improvements in model physics and resolution. We note in this context that shifting from a $2^{\circ}$ resolution state estimate to one at $1^{\circ}$ resolution already improved the ECCO results substantially. Reasons for this improvement are many fold, however, and are not only due to improved model resolution. Rather, enhanced data constraints, the increased estimation period, improved bottom topography, and improved model parameterizations, for example, of ocean eddy transports, all contribute to this improvement.

[49] We expect similar progress and improvements in surface flux estimates over the next few years through the improvements in assimilation approaches. It is anticipated that the method explored here will be much more widely used in the future. The long-term goal is to use this information to improve the quality of surface flux fields available from atmospheric re-analysis efforts, but also to improve medium-range weather predictions by using the information available from ocean data sets. The ultimate goal is an improvement in climate predictions of coupled ocean-atmosphere models.

[50] Acknowledgments. Re-analysis surface forcing fields from the National Center for Environmental Prediction/National Center for Atmospheric Research (NCEP/NCAR) are obtained through a computational grant at NCAR. The adjoint compiler TAF from the company FastOpt was used to create the adjoint general circulation model. The computational support through a NRAC grant from the National Partnership for Computational Infrastructure (NPACI) and through a grant from the National Center for Atmospheric Research is acknowledged. Supported in part through NASA grant NAG5-7857, through NSF grant OCE 9730071, and through two contracts with the Jet Propulsion Laboratory $(958125$ and 1205624). This is a contribution of the Consortium for Estimating the Circulation and Climate of the Ocean (ECCO) funded by the National Oceanographic Partnership Program under grants N00014-99-1-1049 and N00014-99-1-1050.

\section{References}

Bentamy, A., O. Archer, P. Flament, V. Harscoat, C. Maroni, Y. Quilfen, and S. Pouliquen (1998), Mean Surface Wind Fields [CD-ROM], World Ocean Circ. Exp., Halifax, N. S., Can.

Beranger, K., K. Viau, B. Barnier, E. Garnier, J.-M. Moline, and L. Siefridt (1999), An Atlas of Climatic Estimates of Air-Sea Fluxes, Lab. des coulements Gophys. et Ind. (LEGI) IMG, Grenoble, France.

Bonekamp, H., G. van Oldenborgh, and G. Burges (2001), Variational Assimilation of Tropical Atmosphere-Ocean and expendable bathythermograph data in the Hamburg Ocean Primitive Equation ocean general circulation model, adjusting the surface fluxes in the tropical ocean, J. Geophys. Res., 106, 16,693-16,709.

Brydan, H., and S. Imawaki (2001), Large-scale ocean transports, in Ocean Circulation and Climate, Int. Geophys. Ser., vol. 77, edited by G. Siedler, J. Church, and J. Gould, pp. 455-474, Academic, San Diego, Calif.

Chelton, D. B., M. G. Schlax, M. H. Freilich, and R. F. Milliff (2004), Satellite radar measurements reveal short-scale features in the wind stress field over the world ocean, Science, 303, 978-983.
Fairall, C. W., E. F. Bradley, D. P. Rogers, J. B. Edson, and G. S. Young (1996a), Bulk parameterization of air-sea fluxes for TOGA COARE, J. Geophys. Res., 101, 3747-3764.

Fairall, C. W., E. F. Bradley, J. S. Godfrey, G. A. Wick, and G. S. Young (1996b), The cool skin and the warm layer in bulk flux calculations, J. Geophys. Res., 101, 1295-1308.

Fukumori, I. (2001), Data assimilation by models, in Satellite Altimetry and Earth Sciences, edited by L. Fu and A. Cazenave, pp. 237-265, Academic, San Diego, Calif.

Ganachaud, A., and C. Wunsch (2003), Large-scale ocean heat and freshwater transports during the World Ocean Circulation Experiment, J. Clim., 16, 696-705.

Garnier, E., B. Barnier, L. Siefridt, and K. Béranger (2000), Investigating the 15 years air-sea flux climatology from the ECMWF re-analysis project as a surface boundary condition for ocean models, Int. J. Climatol., $20,1653-1673$.

Gent, P. R., and J. C. McWilliams (1990), Isopycnal mixing in ocean models, J. Phys. Oceanogr., 20, 150-155.

Gibson, J. K., P. Kallberg, S. Uppala, A. Hernadez, A. Nomura, and E. Serrano (1997), ERA description, Rep. 1, 72 pp., ECMWF Re-analysis Project, Reading, UK.

Giering, R., and T. Kaminski (1998), Recipes for adjoint code construction, Trans. Math. Software, 24, 437-474.

Grist, J. P., and S. A. Josey (2003), Inverse analysis of the SOC air-sea flux climatology using ocean heat transport constraints, J. Clim, in press.

IFREMER (2000), Mean Surface Wind Field from the ERS-AMI and ADEOS-NSCAT Microwave Scatterometer $1991 / 08 / 05$ to $2000 / 05 / 31$ [CD-ROM], Brest, France.

Josey, S. A., E. C. Kent, and P. K. Taylor (1999), New insights into the ocean heat budget closure problem from analysis of the SOC air-sea flux climatology, J. Clim., 12, 2856-2880.

Kalnay, E., et al. (1996), The NCEP/NCAR re-analysis project, Bull. Am. Meteorol. SOC., 77, 437-471.

Kessler, W. S., G. C. Johnson, and D. W. Moore (2003), Sverdrup and nonlinear dynamics of the Pacific Equatorial Currents, J. Phys. Oceanogr., 33, 994-1008.

Köhl, A., Y. Lu, P. Heimbach, B. Cornuelle, D. Stammer, and C. Wunsch (2002), The ECCO $1^{\circ}$ global WOCE Synthesis, Rep. 20, 30 pp., Univ. of Calif., San Diego, La Jolla, Calif. (Available at http://www.ecco-group. org/reports.html)

Large, W. G., and A. J. G. Nurser (2001), Ocean surface water mass transformation, in Ocean Circulation and Climate, edited by G. Siedler, J. Church, and J. Gould, pp. 317-336, Academic, San Diego, Calif.

Large, W. G., J. C. McWilliams, and S. C. Doney (1994), Oceanic vertical mixing: A review and a model with nonlocal boundary layer parameterization, Rev. Geophys., 32, 363-403.

Levitus, S., R. Burgett, and T. Boyer (1994a), World Ocean Atlas 1994, vol. 3, Salinity, NOAA Atlas NESDIS 3, Natl. Oceanic and Atmos. Admin., Silver Spring, Md.

Levitus, S., R. Burgett, and T. Boyer (1994b), World Ocean Atlas 1994, vol. 4, Temperature, NOAA Atlas NESDIS 4, Natl. Oceanic and Atmos. Admin., Silver Spring, Md.

Levitus, S., J. I. Antonov, J. Wang, T. L. Delworth, K. W. Dixon, and A. J. Broccoli (2001), Anthropogenic warming of Earth's climate system, Science, 292, 267-270.

Liu, W. T., K. B. Katsaros, and J. A. Businger (1979), Bulk parameterizations of air-sea exchanges of heat and water vapor including the molecular constraints at the interface, J. Atmos. Sci., 36, 17221735 .

Lu, Y., K. Ueyoshi, A. Köhl, E. Remy, K. Lorbacher, and D. Stammer (2002), Input data sets for the ECCO Global $1^{\circ}$ WOCE Synthesis, Rep. 18. (Available at http://www.ecco-group.org/reports.html)

Macdonald, A. M., and C. Wunsch (1996), An estimate of global ocean circulation and heat fluxes, Nature, 382, 436-439.

Malanotte-Rizzoli, P. (1996), Modern Approaches to Data Assimilation in Ocean Modeling, 455 pp., Elsevier Sci., New York.

Marotzke, J., R. Giering, Q. K. Zhang, D. Stammer, C. N. Hill, and T. Lee (1999), Construction of the adjoint MIT ocean general circulation model and application to Atlantic heat transport sensitivity, J. Geophys. Res., $104,29,529-29,548$

Marshall, J., A. Adcroft, C. Hill, L. Perelman, and C. Heisey (1997a), A finite-volume, incompressible Navier-Stokes model for studies of the ocean on parallel computers, J. Geophys. Res., 102, 5753-5766.

Marshall, J., C. Hill, L. Perelman, and A. Adcroft (1997b), Hydrostatic, quasi-hydrostatic and non-hydrostatic ocean modeling, J. Geophys. Res., $102,5733-5752$.

McPhaden, M. J., et al. (1998), The Tropical Ocean Global Atmosphere observing system: A decade of progress, J. of Geophys. Res., 103 , $14,169-14,240$. 
Milliff, R. F., W. G. Large, J. Morzel, G. Danabasoglu, and T. M. Chin (1999), Ocean general circulation model sensitivity to forcing from scatterometer winds, J. Geophys. Res., 104, 11,337-11,358.

Moyer, K. A., and R. A. Weller (1997), Observations of surface forcing from the Subduction Experiment: A comparison with global model products and climatological datasets, J. Clim., 10, 2725-2742.

Perry, G. D., P. B. Duffy, and N. L. Miller (1996), An extended data set of river discharges for validation of general circulation models, J. Geophys. Res., 101, 21,339-21,349.

Renfrew, I. A., G. W. K. Moore, P. S. Guest, and K. Bumke (2002), A comparison of surface layer, surface heat flux and surface momentum flux observations over the Labrador Sea with ECMWF analyses and NCEP re-analysis, J. Phys. Oceanogr., 32, 383-400.

Reynolds, R. W., and T. M. Smith (1994), Improved global sea surface temperature analysis using optimum interpolation, J. Clim., 7, 929-948.

Smith, S. R., D. M. Legler, and K. V. Verzone (2001), Quantifying uncertainties in NCEP re-analysis using high-quality research vessel observations, J. Clim., 14, 4062-4072.

Stammer, D. (2003), Ocean mixing estimated through state estimation, submitted for publications.

Stammer, D., C. Wunsch, R. Giering, C. Eckert, P. Heimbach, J. Marotzke, A. Adcroft, C. N. Hill, and J. Marshall (2002), The global ocean circulation during 1992-1997, estimated from ocean observations and a general circulation model, J. Geophys. Res., 107(C9), 3118, doi:10.1029/ 2001JC000888.

Stammer, D., C. Wunsch, R. Giering, C. Eckert, P. Heimbach, J. Marotzke, A. Adcroft, C. N. Hill, and J. Marshall (2003), Volume, heat, and freshwater transports of the global ocean circulation 1993-2000, estimated from a general circulation model constrained by WOCE data, J. Geophys. Res., 108(C1), doi:10.1029/2001JC000937.

Sun, B., L. Yu, and R. A. Weller (2003), Comparisons of surface meteorology and turbulent heat fluxes over the Atlantic: NWP model analyses versus moored buoy observations, J. Clim., 16, 679-695.

Trenberth, K. E., and J. M. Caron (2001), Estimates of meridional atmosphere and ocean heat transports, J. Clim., 14, 3433-3443.
Trenberth, K. E., J. M. Caron, and D. P. Stepaniak (2001), The atmospheric energy budget and implications for surface fluxes and ocean heat transports, Clim. Dyn., 17, 259-276.

Wang, W., and M. J. McPhaden (2001), What is the mean seasonal cycle of surface heat flux in the equatorial Pacific?, J. Geophys. Res., 106, 837857.

Wentz, F. J., C. Gentemann, D. Smith, and D. Chelton (2000), Satellite measurements of sea surface temperature through clouds, Science, 288, $847-850$

Wijffels, S. E. (2001), Ocean transport of fresh water, in Ocean Circulation and Climate: Observing and Modelling the Global Ocean, edited by G. Siedler, J. Church, and J. Gould, pp. 475-488, Academic, San Diego, Calif.

Wijffels, S. E., R. W. Schmitt, H. Bryden, and A. Stigebrand (1992), Transport of freshwater by the ocean, J. Phys. Oceanogr., 22, 155-162.

Working Group on Air-Sea Fluxes (WGASF) (2000), Intercomparison and validation of ocean-atmosphere energy flux fields, final report of the Joint WCRP/SCOR Working Group on Air-Sea Fluxes (SCOR Working Group 110), edited by P. K. Taylor, 306 pp., World Clim. Res. Program, Geneva. Wunsch, C. (1996), The Ocean Circulation Inverse Problem, 442 pp., Cambridge Univ. Press, New York.

S. A. Josey, James Rennell Division, Southampton Oceanography Centre, 254/31, European Way, Southampton S014 3Zh, UK. (sxj@soc.soton. ac.uk)

A. Köhl, D. Stammer, and K. Ueyoshi, Scripps Institution of Oceanography, La Jolla, CA 92093,USA. (akoehl@ucsd.edu; dstammer@ ucsd.edu; ueyoshi@fjord.ucsd.edu)

W. G. Large, Oceanography Center, National Center for Atmospheric Research, 1850 Table Mesa Drive, Boulder, CO 80305, USA. (wily@ucar. edu)

C. Wunsch, Department of Earth, Atmospheric, and Planetary Sciences, Massachusetts Institute of Technology, Room 54-1522, 77 Massachusetts Avenue, Cambridge, MA 02139-4307, USA. (cwunsch@pond.mit.edu) 